\title{
Phytotoxicity of pyrethroid pesticides and its metabolite towards Cucumis sativus
}

\author{
I. Bragança ${ }^{a}$, Paulo C. Lemos ${ }^{b}$, Piedade Barros ${ }^{c}$, Cristina Delerue-Matos ${ }^{a}$, Valentina F. Domingues ${ }^{a, *}$ \\ a REQUIMTE/LAQV-GRAQ Instituto Superior de Engenharia do Porto, Polytechnic Porto, Rua Dr. António Bernardino de Almeida, 431, 4200-072 Porto, Portugal \\ b REQUIMTE/LAQV, Chemistry Dep., FCT/Universidade NOVA de Lisboa, Campus de Caparica, 2829-516 Caparica, Portugal \\ c Health and Environmental Research Center (CISA), School of Allied Health Sciences of Porto, Polytechnic Porto, Rua Valente Perfeito, $322,4400-330$ Vila Nova de Gaia, Portugal
}

Pyrethroid pesticides residues have been frequently detected in soils and have been recognized to contribute to soil toxicity. The phytotoxic impact of pesticides was evaluated in Cucumis sativus (C. sativus) seeds. Percentage of seed germination, root elongation, shoot length and leaf length were considered as endpoints to assess the possible acute phytotoxicity of soil by the exposure to pyrethroid pesticides (cypermethrin, deltamethrin and cyhalothrin) and its metabolite phenoxybenzoic acid (3-PBA),

in a concentration range between 50 and 500 ' $\mathrm{g} \mathrm{kgcel}$. For germination percentage, it was only observed a negative impact when seeds were exposed to the metabolite. Cypermethrin showed impact in the three studied endpoints of seed development, while deltamethrin merely affected the root length. Concerning pigments content, it can be said that chlorophylls and total carotenoids median values increased for cypermethrin and deltamethrin. This increase was more pronounced to deltamethrin in joint effect with the organic solvent dimethyl sulphoxide (DM SO). When exposed to cyhalothrin and 3-PBA, no statistically significant differences were observed for $C$. sativus seeds to all the assessed endpoints of seed development and the investigated pigments content. This research brings new data concerning the relative sensitivity of $C$. sativus seeds to pyrethroids pesticides commonly found in agricultural facilities, as well as critical understanding and development of using C. sativus for phytotoxicity assessments efforts for pesticide exposures.

\author{
Keywords: \\ Phytotoxicity \\ Pyrethroid pesticides \\ 3-PBA \\ Germination \\ Cucumis sativus \\ Chlorophylls
}

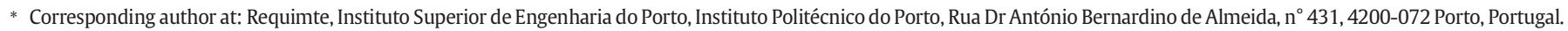
E-mail address: vfd@isep.ipp.pt (V.F. Domingues).
} 


\section{Introduction}

Pyrethroids pesticides are widely used as insecticides in agriculture, veterinary and domestic applications to control insect pests (Albaseer et al., 2011; Bronshtein et al., 2012). Synthetic pyrethroids were developed to preserve the insecticidal activity of pyrethrins and to enhance physical and chemical properties, as the stability to light (Gosselin et al., 1984). Pyrethroids differ from many other pesticides in that they have three typical characteristics: extreme hydrophobicity, rich stereochemistry (contain one to three chiral centers) and broad-spectrum high-level insecticidal activity. These pyrethroids represent a significant improvement when compared to other insecticide classes due to their very low non-target mammals and birds toxicity and better selectivity to target species (Luo and Zhang, 2011). The pyrethroids are the most common active ingredients in commercially available insect sprays and are the dominant pesticides for malaria control (Raghavendra et al., 2011; Ranson et al., 2011). Depending on the type of soil and the initial concentration the half-lives of pyrethroids in soil have been estimated to be between 17.1 and 52.1 and 8.3-105.3 days for cypermethrin and deltamethrin, respectively (Cycoń and Piotrowska-Seget, 2016).

Pyrethroids in the terrestrial environment occur mainly via spray drift but accidental spills and direct application to soil can also arise (Palmquist et al., 2012). Pyrethroids dynamic in soils is dependent on soil physical-chemical characteristics. Pyrethroids strongly bind to soil particles and organic matter due to their highly hydrophobic properties (Gu et al., 2008; Oudou and Hansen, 2002; Xu et al., 2015). These pesticides residues have been frequently detected in soils and sediments and have been recognized to contribute to sediment toxicity. Sediments in California's Central Valley were tested and in three-fourths of the toxic samples, pyrethroids exceeded concentrations expected to cause toxicity. Bifenthrin reached a maximum of $32 \mu \mathrm{gg}^{-1}$ in sediment much higher than the $\mathrm{LC}_{50}$ of 3-10 $\mu \mathrm{g} \mathrm{kg}^{-1}$ for some invertebrates (Hyalella azteca or Chironomus dilutus). This study (Weston et al., 2013) reaffirms the contribution of pyrethroids to sediment toxicity even though sampling was not specifically focused on areas of high pyrethroids use. Pyrethroids were detected at maximum concentrations of $57.0 \mu \mathrm{g} \mathrm{kg}^{-1}$ before plow and $62.3 \mu \mathrm{g} \mathrm{kg}^{-1}$ during rice production in the soil in Mediterranean paddy fields, being resmethrin and cyfluthrin the compounds found at higher concentrations (Aznar et al., 2017). Pyrethroids presence was much higher in the sediments of creeks within a residential neighborhood near Roseville (Weston et al., 2005), where cyfluthrin, permethrin, bifenthrin, and cypermethrin were found at maximum concentrations of $169,335,437$ and $736 \mu \mathrm{gg}^{-1}$, respectively.

Pyrethroids in soil follow different pathways such as degradation, sorption-desorption, volatilization, uptake by plants and can also be transported into surface waters and groundwaters (Cycoń and Piotrowska-Seget, 2016). Microbial degradation of pyrethroids appears to be a significant breakdown route of such pesticides (Palmquist et al., 2012). The main process of environmental degradation of pyrethroids consists in the hydrolysis of carboxylester linkage that results most frequently in the production of cyclopropane acid and an alcohol moiety (3-phenoxybenzyl alcohol). The 3-phenoxybenzyl alcohol is rapidly converted to 3-phenoxybenzoic acid (3-PBA). 3-PBA frequently accumulates in the soil as well as the others metabolites referred above (Chen et al., 2011). Tyler et al. (2000) found that cyclopropane, permethrin acid, 3-phenoxybenzyl alcohol and 3-phenoxybenzoic acid, metabolites of environmental permethrin pyrethroid degradation, are of greater concern than their parent compound owing to their ability to interact with steroids hormone receptors. These metabolites in the environment can modulate and/or disrupt the endocrine systems of animals.

Pyrethroids raise environmental concerns due to their increasing and intensive use and potential effects on aquatic ecosystems as they are highly toxic to fish and invertebrates (Antwi and Reddy, 2015;
Haya, 1989; Zhang et al., 2011). There are many studies documenting toxicological effects of pesticides on plants but studies tended to focus on herbicide effects in crop species (Gomes et al., 2017; Wagner and Nelson, 2014).

The increasing and widening use of pyrethroid insecticides cannot only cause residues in the soil but even lead to detrimental effects on plants and other non-target organisms, which necessitates a thorough understanding of their phytotoxicity. Research on the effects of pyrethroids on seed germination are scarce (Hanley and Whiting, 2005; Moore and Locke, 2012). Subsequently, a phytotoxic impact of these pesticides on soil should be assessed. Plant damage due to the application of pesticides is known as phytotoxicity. Pesticide phytotoxicity appears in several ways on plants, causing the studied compound an impact on plant characteristics. Plants are at their most sensitiveness to chemical's application during the early stages of life (Hewitt and Rennie, 1986). Inhibition of germination or on the root, shoot, and leaf development are the main areas of interest in studies on phytotoxicity (Kapanen and Itävaara, 2001). Seed germination and development can be affected by pyrethroid pesticides application. Hanley and Whiting (2005) reported that deltamethrin decreased the seedling growth of Capsella bursa-pastoris L. and Poa annua L. With increasing concentrations of cypermethrin and fenvalerate the germination rates of Pennisetum pedicellatum Trin showed a tendency to decrease (Dubey and Fulekar, 2011). Germination percentages of primary roots of Glycine max L. decreased with increasing cypermethrin concentration (Aksoy and Deveci, 2012). Visible phytotoxic effects can also occur, as chlorosis, necrosis, wilting and leaf and stem deformations (Wang and Williams, 1988). Cucumber and lettuce are the biological test species recommended by the U.S. Environmental Protection Agency for toxicity testing and environmental assessment (USEPA, 1996). The terrestrial plants assays for testing chemicals are considered valid when the following performance criteria are met for water controls: the seedling emergence must be at least 70\%; the seedlings do not exhibit visible phytotoxic effects (e.g. chlorosis, necrosis, wilting, leaf and stem deformations); the plants exhibited only normal variation in growth and morphology for that species, and the mean survival of emerged control seedlings is at least $90 \%$ for the duration of the study (OECD, 2006).

The toxicity and the ecological risks in terrestrial environments of the mixtures of organic pollutants can be ascertained by the inhibition of photosynthesis efficiency (Gonzalez-Naranjo et al., 2015). Photosynthesis sustains nearly all life on Earth since it is largely responsible for providing oxygen present in Earth's atmosphere (Johnson and Portland Press, 2016). The measure of Chlorophyll- $a$ (Ch $a$ ), Chlorophyll- $b(\mathrm{Ch} b)$ and total carotenoids $(\mathrm{C} \mathrm{x}+\mathrm{c})$ are powerful tools to determine photosynthetic activity and so to evaluate the stress impact in plants (Zarco-Tejada et al., 2009). External factors can undesirable change and influence plants, causing different physiological responses (Ibanez et al., 2010). The Chlorophyll $a / b$ ratio $\left(\mathrm{Ch}_{a / b}\right)$ is a conceivable indicator of nitrogen partitioning within a leaf since it can be positively correlated with the ratio of photosystem II cores to light harvesting chlorophyll-protein complex (Hikosaka and Terashima, 1995). Carotenoids and anthocyanins have also to be considered since they are the main pigments known to be involved in protecting plant organs from stress. Also, carotenoids additionally function as non-enzymatic antioxidants (Strzalka et al., 2003).

The aim of this study was to evaluate the phytotoxic effects of three synthetic pyrethroids (cypermethrin, deltamethrin, and cyhalothrin) and of one of their metabolites (3-PBA) in Cucumis sativus (cucumber) seeds. Given the sensitivity of seeds to chemicals, the effects of different concentrations $\left(50,125,200,350\right.$ and $500 \mathrm{\mu g} \mathrm{kg}^{-1}$ soil dry weight) of these compounds on seed germination, subsequent early growth of seedlings and pigments content of leafs were the main parameters followed. To the best of the authors' knowledge, this is the first study on the pyrethroid pesticides (cypermethrin, deltamethrin, and cyhalothrin) and its metabolite (3-PBA) phytotoxicity to $C$. sativus germination, the seedling grown and photosynthesis. 


\section{Materials and methods}

\subsection{Study pesticides}

For this study, three pyrethroid pesticides and its major metabolite were used: $\alpha$-cypermethrin, $\Lambda$-cyhalothrin, deltamethrin, and 3-PBA. Pesticides and metabolite standards (purity $\geq 95.4 \%$ ) were obtained from Chemservice (West Chester, PA, USA) and Sigma-Aldrich Co. (Steinheim, Germany), respectively. The dimethyl sulphoxide (DMSO) (p.a., dried) was also obtained from Sigma-Aldrich Co. A range of pesticides concentrations was chosen for this study in anticipation of generating comparative-response data. Stock solutions of pyrethroids and 3PBA were prepared in DMSO due to their insolubility in water (concentrations ranging between 600 and $700 \mathrm{ppm}$ ) and stored in the dark at 4 ${ }^{\circ} \mathrm{C}$. This polar aprotic solvent is less toxic than other members of its class and is commonly used in biological tests as a vehicle for non-water-soluble chemicals (Yu et al., 2017). DMSO was utilized in a small percentage $(0.4 \%)$ and a control setting for DMSO was used to observe if the effects in the treated seeds were due to the chemical and not to the solvent/vehicle. The five working solutions used to contaminate the soils were prepared daily by dispersing amounts of stock solutions in water obtaining the following concentration: $0.250,0.625,1.00,1.75$ and $2.50 \mathrm{mg} \mathrm{L}^{-1}$ for each pyrethroid and 3-PBA. The DMSO amount placed in each working solution was the same, $0.4 \%$. DMSO was used in all assays (including chlorophyll extraction) because many authors reported the merits of this solvent with high efficiency also in pigments extractions (Sumanta et al., 2014) even when concentrations were too low (Porra, 2002; Wright et al., 1997).

\subsection{Test organism and artificial soil matrix}

Cucumber seeds, Cucumis sativus var. marketmore, were acquired from Casa Hortícola (Porto, Portugal). The seeds were kept in their original paper packages and stored in the dark in a zip-lock sealed bag at $4{ }^{\circ} \mathrm{C}$.

A certified artificial sandy soil from MIBAL - Minas de Barqueiros S.A. (Apúlia, Portugal) was used to perform all the toxicity tests. Artificial sandy soils are used for testing chemicals when a minimal variability of the natural soil is desired and to increase the comparability of the several test results (OECD, 2006). This sandy soil is predominantly siliceous with grain dimensions above $1.4 \mathrm{~mm}$ and composed mainly of Quartz. The soil was physical-chemical characterized according to OECD (2006) guidelines. The procedures for physical-chemical characterization (total organic carbon (TOC), water holding capacity (WHC), pH and conductivity values, organic matter (OM) content) of the sandy soil used was previously reported by Braganca et al. (2012) and Margesin and Schinner (2005).

\subsection{Acute toxicity seedling growth test}

Acute ecotoxicity tests were prepared according to the recommended condition and procedures for conducting reference toxicity tests on soil using terrestrial plants (EPS 1/RM/45 report, Canada) and to OCDE (2006) guidelines for the testing of chemicals.

For acute ecotoxicity tests in the soil, the concentrations of pesticides and 3-PBA used were 50,125, 200, 350 and $500 \mu \mathrm{gg}^{-1}$ soil dry weight. Germination assays were carried out by placing ten replicates of five individual $C$. sativus seeds per replicate, for a total of 50 seeds per treatment. Tests were conducted using $140 \times 20 \mathrm{~mm}$ disposable plastic Petri dishes with $100 \mathrm{~g}$ of pre-dried sandy soil. The soil was moistened with either $20 \mathrm{~mL}$ ( 70\% of water-holding capacity) of deionised water (Water controls), or deionised water with $0.4 \%$ of DMSO (DMSO controls) or with treatment solutions using a Pasteur pipette (dropwise in soil surface simulating a watering system) being Petri dishes sealed with parafilm. The Petri dishes were arranged in a completely random order, placed in a growth chamber (Binder, KBWF 240, USA), equipped with daylight fluorescent lamps (10,000 lx per light cassette), during a total of $168 \mathrm{~h}$. The temperature used for both the first $48 \mathrm{~h}$ carried out in darkness, and the following photoperiods of $16 \mathrm{~h}$ of light (simulating day) was $24 \pm 2{ }^{\circ} \mathrm{C}$, the lasts alternated with $8 \mathrm{~h}$ of darkness at $15 \pm 2{ }^{\circ} \mathrm{C}$ (simulating night). After seven days of exposure, the germination parameters (root, shoot, and leaf length) were measured with a certified electronic digital caliper (Paget Trading Ltd., Woodrow London SE18 5DH, UK).

\subsection{Chlorophylls and carotenoids}

All the fresh leafs sampled per Petri dish (equivalent to one replicate) were removed with a scissor, weighted, and extracted with solvent added in the proportion of $2 \mathrm{~mL}$ of DMSO per $25 \mathrm{mg}$ of fresh leaf. The sample was homogenized for $15 \mathrm{~min}$ in the ultrasonic bath (Sonorex Digital 10P, Bandelin) (Giri et al., 2013). The chlorophyll extract was later analysed using 96-well plates, in a Synergy HT W/TRF Multimode Microplate Reader (BioTek Instruments, Winooski, VT, USA) at 480,0 649.1 and 665.1 nm against DMSO blank. The quantification of Chlorophyll- $a\left(\mathrm{Ch}_{a}\right)$, Chlorophyll- $b\left(\mathrm{Ch}_{b}\right)$ and carotenoids $\left(C_{x}+c\right)$ was performed by using the Eqs. (1), (2) and (3), respectively (Wellburn, 1994):

$$
\begin{aligned}
& \mathrm{Ch}_{a}=12.47 \mathrm{~A}_{665.1}-3.62 \mathrm{~A}_{649.1} \\
& \mathrm{Ch}_{b}=25.06 \mathrm{~A}_{649.1}-6.5 \mathrm{~A}_{665.1} \\
& \mathrm{C}_{\mathrm{x}+\mathrm{c}}=\left(1000 \mathrm{~A}_{480}-1.29 \mathrm{Ch}_{a}-53.78 \mathrm{Ch}_{b}\right) / 220
\end{aligned}
$$

\subsection{Statistical analysis}

Data from acute ecotoxicity tests were tested for normality (ShapiroWilk). The non-parametric test Kruskal-Wallis was applied due to the non-normal distribution of the data with a significance threshold of $\mathrm{p}<0.05$. After that, a post-hoc pairwise comparison using the Dunn-Bonferroni approach was applied. Data were expressed as median and range. All statistical analyses were performed with SPSS software, version 20.0 (SPSS Inc., Chicago, Illinois).

\section{Results and discussion}

\subsection{Germination}

The knowledge of the properties of the soil exploited in agricultural activities is important considering soil management and plant growth. For the specific soil used in these assays the parameter values determined were: conductivity $\left(8.47 \pm 0.01 \mathrm{mS} \mathrm{m}^{-1}\right), \mathrm{pH}(4.9 \pm 0.3)$, WHC $(33.5 \pm 0.06 \%)$, TOC $(0 \%)$ and OM $(0.07 \pm 0.01 \%)$ in the average range for this type of sandy soil.

Concerning the toxicity tests performed, C. sativus seeds germination percentages were not affected when exposed to increased pyrethroids pesticides concentrations between 50 and $500 \mu \mathrm{kg}^{-1}$ (Fig. 1) and also not significantly different for the several pesticides tested. The median percentages of germination for this study were 100,80 and 100 for cypermethrin, deltamethrin, and cyhalothrin, respectively, being no significant differences in germination observed between controls and exposed pyrethroids seeds. The range of germination values (\%) had a lower bound for almost all the concentration tested, however, no trend was found between germination and increasing levels of pesticides. Similar findings were reported by Moore and Locke (2012) to Typha latifolia when exposed to three pesticides, one of them a pyrethroid (permethrin). Hanley and Whiting (2005) determine the toxicological effects of deltamethrin and dimethoate to six species of weeds. They found that the applied insecticides had no significant effect on 

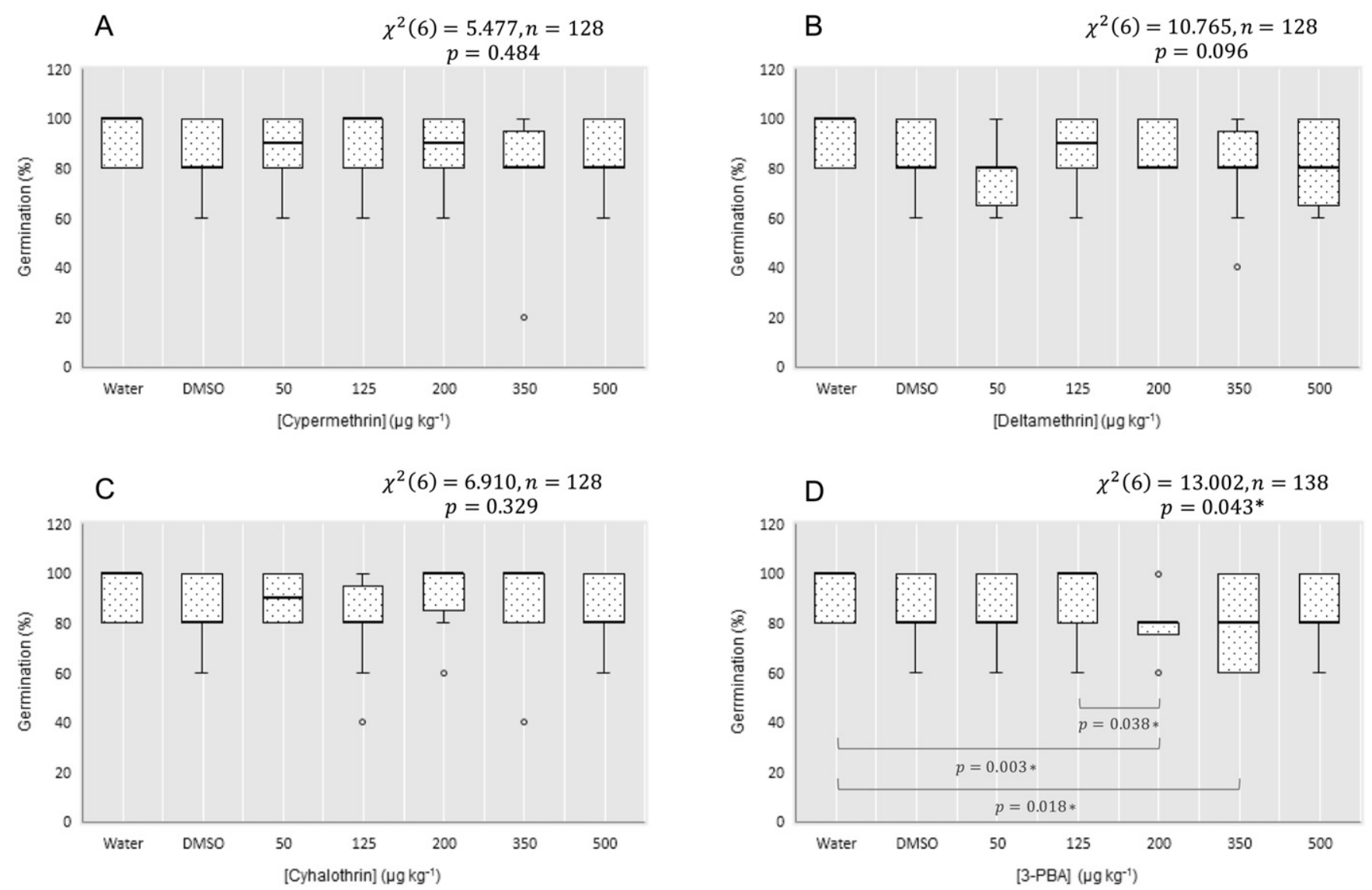

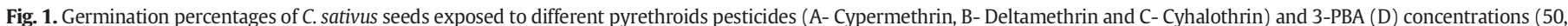

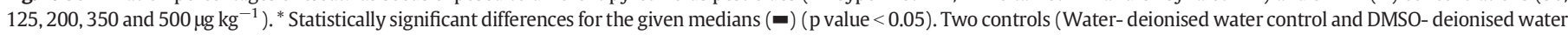
with $0.4 \%$ of DMSO solvent control) were used to evaluate differences in seed development.

seed germination but for Capsella bursa-pastoris and Poa annua seedling growth was decreased by exposure to deltamethrin.

For 3-PBA it was possible to observe significant differences in seed germination distribution across categories, considering the concentrations used ( $p=0.043$ ). Differences were found between the Water control and 3-PBA concentrations of $200 \mu \mathrm{kg}^{-1}(\mathrm{p}=0.003)$ and 350 $\mu \mathrm{kg}^{-1}(\mathrm{p}=0.018)$ while no differences were found for the same concentrations and DMSO control. It's likely that the combined effect of DMSO and 3-PBA concentration was most toxic to seed germination that the single effect of this compound. Since no statistically significant differences were found between the Water and DMSO controls no specific impact can be attributed to DMSO at the concentration used. Kumar et al. (2013) also used DMSO to dissolve permethrin. The toxicity of the pesticide was evaluated after its dispersion in water or by means of a nanoformulated permethrin, being applied to various non-target organisms including the Cucumis sativus, where DMSO also showed no significant effect on both root elongation and germination rate (\%).

\subsection{Root, shoot and leaf development}

Commercially used pesticides, such as dimethoate and deltamethrin, are known to exert phytotoxic effects on both plant germination and growth, impacting enzymatic pathways involved in such processes (Hanley and Whiting, 2005). Kapanen and Itävaara (2001) concluded that statistically significant changes in seedling grown tests compared to root, shoot or leaf lengths for any of the tests exposed to composted materials indicate a phytotoxic effect with the same cause. Table 1 shows the results obtained for phytotoxic effects in $C$. sativus seeds development (root, shoot and leaf length) after the application of different pyrethroid insecticides concentrations. Although germination was relatively unaffected by insecticide as previously mentioned, seedling growth was significantly changed by insecticide application. The results suggested that $C$. sativus seed growth may be extremely sensitive to some pyrethroids application, in this case for three out of the four compounds tested, being some parameters more sensitive than others. Seed germination tests measure soil toxicity directly, while root elongation, shoot, and leaf length tests consider the indirect effects of water constituents that may be present in the environment. Many studies indicated that the root system was more sensitive to environmental toxicity than the other considered endpoints (Liu et al., 2009; Rede et al., 2016). The median values of root elongation for Water and DMSO controls were not statistically significantly different and were equal to $55.28 \mathrm{~mm}$ and $58.16 \mathrm{~mm}$, respectively (Table 1 ). For the cypermethrin concentration of $125 \mu \mathrm{g} \mathrm{kg}{ }^{-1}$ the maximum median root length (64.85 $\mathrm{mm}$ ) was obtained, showing an increase of $17 \%$ and $12 \%$ when compared to the water and DMSO controls, respectively. For the same concentration deltamethrin exhibited also the highest median difference when compared to the controls (16\% and $10 \%$ for water and DMSO controls, respectively). For the metabolite 3-PBA, the differences were not statistically significant considering a significance threshold of $0.05(\mathrm{p}=0.069)$ but interestingly the maximum median of root length for 3-PBA was also found for the same concentration with a value of $61.63 \mathrm{~mm}$. Root elongation results were not conclusive in terms of pyrethroid pesticides toxicity. A clear difference between the pesticides concentration and the DMSO was not observed which suggests that only the combined effect of the organic solvent plus the pyrethroid pesticide had influence and not the individual effect of each compound. For the pesticides used in the current study, shoot and leaf development were 
Table 1

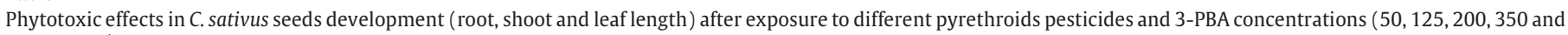

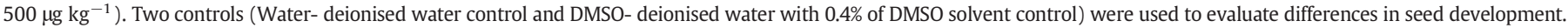

\begin{tabular}{|c|c|c|c|c|c|}
\hline \multirow[t]{2}{*}{ Compound } & & \multirow[t]{2}{*}{ Concentration $\left(\mu \mathrm{kg}^{-1}\right)$} & Root elongation (mm) & \multirow[t]{2}{*}{ Shoot length (mm) } & \multirow[t]{2}{*}{ Leaf length (mm) } \\
\hline & & & Median (min-max) & & \\
\hline \multirow[t]{9}{*}{ Cypermethrin } & Water & 0 & $55.28^{\mathrm{a}}(6.83-89.70)$ & $11.16^{\mathrm{a}}(3.09-23.35)$ & $11.52^{\mathrm{a}}(5.51-20.08)$ \\
\hline & DMSO & 0 & $58.16^{\mathrm{ab}}(13.06-90.60)$ & $10.88^{\mathrm{a}}(3.43-24.77)$ & $11.19^{\mathrm{ac}}(7.11-20.09)$ \\
\hline & & 50 & $59.88^{\mathrm{ab}}(23.49-89.43)$ & $8.07^{\mathrm{b}}(2.84-17.55)$ & $10.94^{\mathrm{ac}}(8.33-17.03)$ \\
\hline & & 125 & $64.85^{\mathrm{b}}(9.13-86.75)$ & $7.56^{\mathrm{b}}(3.85-19.02)$ & $9.91^{\mathrm{bc}}(6.56-17.80)$ \\
\hline & & 200 & $57.77^{\mathrm{ab}}(29.8-83.02)$ & $8.12^{\mathrm{b}}(2.41-18.46)$ & $10.81^{\mathrm{c}}(8.19-16.38)$ \\
\hline & & 350 & $59.97^{\mathrm{ab}}(2.39-88.57)$ & $7.51^{\mathrm{b}}(1.68-21.41)$ & $10.14^{\mathrm{ac}}(8.86-18.63)$ \\
\hline & & 500 & $64.54^{\mathrm{b}}(21.60-87.57)$ & $7.49^{\mathrm{b}}(3.91-21.71)$ & $10.44^{\mathrm{ac}}(7.90-18.72)$ \\
\hline & & Kruskal-Wallis & $\chi^{2}(6)=13.247$ & $\chi^{2}(6)=45.798$ & $\chi^{2}(6)=18.872$ \\
\hline & & Total $\mathrm{n}=562$ & $\mathrm{p}=0.039^{*}$ & $\mathrm{p}<0.001^{*}$ & $\mathrm{p}=0.004^{*}$ \\
\hline \multirow[t]{9}{*}{ Deltamethrin } & Water & 0 & $55.28^{\mathrm{a}}(6.83-89.70)$ & $11.16(3.09-23.35)$ & $11.52(5.51-20.08)$ \\
\hline & DMSO & 0 & $58.16^{\mathrm{ab}}(13.06-90.60)$ & $10.88(3.43-24.77)$ & $9.67(7.11-20.09)$ \\
\hline & & 50 & $63.80^{\mathrm{b}}(35.71-99.49)$ & $9.11(4.29-24.89)$ & $10.24(7.52-17.80)$ \\
\hline & & 125 & $64.16^{\mathrm{b}}(4.94-99.68)$ & $9.99(4.23-23.42)$ & $10.91(6.67-20.95)$ \\
\hline & & 200 & $57.65^{\mathrm{ab}}(10.06-91.81)$ & $10.21(4.40-20.18)$ & $11.37(6.97-17.49)$ \\
\hline & & 350 & $57.50^{\mathrm{ab}}(26.62-103.05)$ & $9.77(3.33-25.26)$ & $10.12(7.30-19.78)$ \\
\hline & & 500 & $59.19^{\mathrm{ab}}(15.61-95.75)$ & $9.84(4.94-22.78)$ & $10.47(7.60-17.83)$ \\
\hline & & Kruskal-Wallis & $\chi^{2}(6)=14.066$ & $\chi^{2}(6)=2.675$ & $\chi^{2}(6)=7.964$ \\
\hline & & Total $\mathrm{n}=554$ & $\mathrm{p}=0.029^{*}$ & $\mathrm{p}=0.848$ & $\mathrm{p}=0.241$ \\
\hline \multirow[t]{9}{*}{ Cyhalothrin } & Water & 0 & $55.28(6.83-89.70)$ & $11.16(3.09-23.35)$ & $11.52(5.51-20.08)$ \\
\hline & DMSO & 0 & $58.16(13.06-90.60)$ & $10.88(3.43-24.77)$ & $11.19(7.11-20.09)$ \\
\hline & & 50 & $53.43(13.14-103.49)$ & $9.52(3.40-26.41)$ & $12.80(6.84-20.33)$ \\
\hline & & 125 & $52.48(11.96-82.22)$ & $11.11(3.87-23.18)$ & $12.03(8.65-19.14)$ \\
\hline & & 200 & $57.22(13.77-97.41)$ & $9.94(4.63-21.45)$ & $11.11(8.60-17.60)$ \\
\hline & & 350 & $58.05(22.77-91.83)$ & $12.17(5.26-21.13)$ & $12.99(8.26-18.53)$ \\
\hline & & 500 & $48.15(9.26-96.54)$ & $14.03(3.22-26.22)$ & $13.26(8.30-19.40)$ \\
\hline & & Kruskal-Wallis & $\chi^{2}(6)=7.904$ & $\chi^{2}(6)=1.769$ & $\chi^{2}(6)=6.845$ \\
\hline & & Total $n=562$ & $\mathrm{p}=0.245$ & $\mathrm{p}=0.940$ & $\mathrm{p}=0.335$ \\
\hline \multirow[t]{9}{*}{ 3-PBA } & Water & 0 & $55.28(6.83-89.70)$ & $11.16(3.09-23.35)$ & $11.52(5.51-20.08)$ \\
\hline & DMSO & 0 & $58.16(13.06-90.60)$ & $10.88(3.43-24.77)$ & $11.19(7.11-20.09)$ \\
\hline & & 50 & 56.46 (24.19-94.69) & $13.08(4.06-25.04)$ & $11.55(8.00-18.34)$ \\
\hline & & 125 & $61.63(28.60-105.25)$ & $12.41(3.26-25.13)$ & $11.64(7.09-19.90)$ \\
\hline & & 200 & $57.42(27.29-86.62)$ & $10.69(5.68-24.70)$ & $11.42(7.66-18.19)$ \\
\hline & & 350 & $59.99(18.26-102.68)$ & $11.85(4.87-23.03)$ & $11.38(6.26-19.49)$ \\
\hline & & 500 & $52.61(27.43-90.07)$ & $11.60(5.10-23.76)$ & $11.42(6.69-19.07)$ \\
\hline & & Kruskal-Wallis & $\chi^{2}(6)=11.690$ & $\chi^{2}(6)=3.965$ & $\chi^{2}(6)=1.752$ \\
\hline & & Total $n=597$ & $\mathrm{p}=0.069$ & $\mathrm{p}=0.681$ & $\mathrm{p}=0.941$ \\
\hline
\end{tabular}

* Statistically significant differences for a p value $<0.05$. The same letters $(a-i)$ in a row that the given medians are not statistically different $(\mathrm{p}>0.05)$.

only statistically significantly different for cypermethrin exposure. A decrease of $25-31 \%$ of shoot length was observed on cucumber seeds expose to different cypermethrin concentrations when compared to DMSO controls ( $p$ values $<0.006$ ). On leaf development, a decrease in leaf length for the $125 \mathrm{\mu g} \mathrm{kg}^{-1}$ cypermethrin concentration when compared with the DMSO control $(\mathrm{p}=0.001)$ was also observed.

Since the $125 \mu \mathrm{gg}^{-1}$ concentration was the one that exhibits more effect in the three endpoints of seed development this was the concentration chosen to compare the four pesticides toxicity. No differences in root length were found between the tested compounds for this concentration. For shoot and leaf lengths, it was notable a difference between cypermethrin and the other compounds ( $p$ values $<0.007$ ) which support the toxic effects of cypermethrin on cucumber seed development when compared to the others tested compounds. In the cyhalothrin case, no statistically significant differences were observed for all the assessed investigated endpoints development (root elongation, shoot and leaf length) towards $C$. sativus seeds, suggesting that this insecticide was the least toxic to cucumber seed germination.

\subsection{Chlorophylls and carotenoids}

The experimental data for $\mathrm{Ch}_{a}, \mathrm{Ch}_{b}$ and $\mathrm{C}_{\mathrm{x}}+{ }_{\mathrm{c}}$ are shown in Table 2 . An increase on chlorophylls ( $\mathrm{Ch}_{a}$ from 3.80 of water and 4.55 of DMSO to a maximum of $5.57 \mu \mathrm{g} / \mathrm{mL}$ ) and total carotenoids median values (from 0.89 of water and 1.00 of DMSO to a maximum of $1.22 \mu \mathrm{g} / \mathrm{mL}$ ) on the leaves were noticed for cypermethrin. Cucumis leaves treated with incremental doses of cypermethrin dissolved in DMSO showed a significant increase in carotenoids $(\mathrm{p}=0.034)$ comparing the control with leaves treated with water (Table 2). Identical results were observed to deltamethrin with an increase on chlorophylls (Cha achieving $6.78 \mu \mathrm{g} / \mathrm{mL}$ ) and total carotenoids median values (achieving $1.36 \mu \mathrm{g}$ / $\mathrm{mL}$ ) on the leaves. Chlorophylls and carotenoids content were statistically significant different ( $p$ values $<0.008$ ) along the deltamethrin concentration distribution that seems to be due to the joint effect of organic solvent (DMSO) and the pyrethroid pesticide. In all the cases, it was observed statistically significant differences between the water and the DMSO controls. The results suggest that cypermethrin and deltamethrin application triggers mechanisms that could contribute to different protective strategies for $C$. sativus as it was previously described for $A$. hortensis and A. rosea when exposed to metals (Kachout et al., 2015). A reflection of this process was observed for carotenoids that may undergo a high turnover under photo-oxidative stress due to chemical quenching of singlet oxygen (Edge and Truscott, 1999).

Deltamethrin can have some effect on the system $\mathrm{N}$ availability, probably involving Ribulose-1,5-bisphosphate carboxylase/oxygenase (Rubisco), PSII and/or LHCII. The $\mathrm{Ch}_{a / b}$ ratio was 5-7\% higher for different deltamethrin pesticide concentrations when compared to the DMSO control being this increase significantly different $(\mathrm{p}<0.018)$. The $\mathrm{Ch}_{a / b}$ ratio is predicted to respond to light and $\mathrm{N}$ availability and $\mathrm{Ch}_{a / b}$ ratios should increase with decreasing $\mathrm{N}$ availability (Hikosaka and Terashima, 1995). When $\mathrm{N}$ supply becomes limiting under high light intensity, the proportional allocation of $\mathrm{N}$ to photosystem II (PSII) should increase at the cost of decreased $\mathrm{N}$ allocation to Rubisco. In contrast, $\mathrm{N}$ allocation to light harvesting chlorophyll-protein complex (LHCII) is 
Table 2

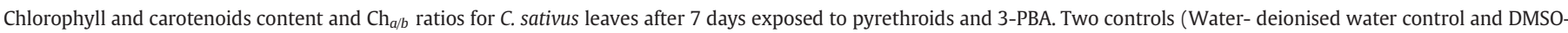
deionised water with $0.4 \%$ of DMSO solvent control) were used to evaluate differences in seed development.

\begin{tabular}{|c|c|c|c|c|c|c|}
\hline \multirow[t]{2}{*}{ Compound } & & \multirow[t]{2}{*}{ Concentration $\left(\mu \mathrm{kg}^{-1}\right)$} & $\mathrm{Ch}_{a}(\mu \mathrm{g} / \mathrm{mL})$ & \multirow[t]{2}{*}{$\mathrm{Ch}_{b}(\mu \mathrm{g} / \mathrm{mL})$} & \multirow[t]{2}{*}{$\mathrm{Ch}_{a / b}$} & \multirow[t]{2}{*}{$\mathrm{C}_{\mathrm{x}}+\mathrm{c}(\mu \mathrm{g} / \mathrm{mL})$} \\
\hline & & & Median (min-max) & & & \\
\hline \multirow[t]{9}{*}{ Cypermethrin } & Water & 0 & $3.80(0.88-10.20)$ & $1.16(0.33-2.89)$ & $3.36(2.68-3.75)$ & $0.89^{\mathrm{a}}(0.40-1.95)$ \\
\hline & DMSO & 0 & $4.55(1.63-12.08)$ & $1.36(0.52-3.36)$ & $3.38(2.83-4.34)$ & $1.00^{\mathrm{b}}(0.53-2.15)$ \\
\hline & & 50 & $4.80(1.48-11.49)$ & $1.45(0.50-3.66)$ & $3.25(2.98-3.57)$ & $1.13^{\mathrm{ab}}(0.41-1.83)$ \\
\hline & & 125 & $5.01(1.86-6.88)$ & $1.50(0.60-1.95)$ & $3.38(2.96-3.63)$ & $1.10^{\mathrm{ab}}(0.63-1.44)$ \\
\hline & & 200 & $5.64(1.74-11.26)$ & $1.57(0.67-3.41)$ & $3.38(2.59-3.72)$ & $1.20^{\mathrm{b}}(0.64-2.08)$ \\
\hline & & 350 & $5.67(2.50-7.19)$ & $1.66(0.75-2.19)$ & $3.42(3.14-3.61)$ & $1.22^{\mathrm{b}}(0.54-1.49)$ \\
\hline & & 500 & 5.57 (3.29-9.94) & $1.58(0.97-2.87)$ & $3.41(3.01-3.68)$ & $1.22^{\mathrm{b}}(0.75-1.91)$ \\
\hline & & Kruskal-Wallis & $\chi^{2}(6)=11.322$ & $\chi^{2}(6)=11.697$ & $\chi^{2}(6)=3.725$ & $\chi^{2}(6)=13.635$ \\
\hline & & Total $n=130$ & $\mathrm{p}=0.079$ & $\mathrm{p}=0.069$ & $\mathrm{p}=0.710$ & $\mathrm{p}=0.034^{*}$ \\
\hline \multirow[t]{9}{*}{ Deltamethrin } & Water & 0 & $3.80^{\mathrm{a}}(0.88-10.20)$ & $1.16^{\mathrm{a}}(0.33-2.89)$ & $3.36^{\mathrm{a}}(2.68-3.75)$ & $0.89^{\mathrm{a}}(0.40-1.95)$ \\
\hline & DMSO & 0 & $4.55^{\mathrm{b}}(1.63-12.08)$ & $1.36^{\mathrm{b}}(0.52-3.36)$ & $3.38^{\mathrm{a}}(2.83-4.34)$ & $1.00^{\mathrm{b}}(0.53-2.15)$ \\
\hline & & 50 & $6.90^{\mathrm{b}}(2.19-12.89)$ & $1.93^{\mathrm{b}}(0.65-3.57)$ & $3.56^{\mathrm{b}}(3.24-3.73)$ & $1.37^{\mathrm{b}}(0.60-2.38)$ \\
\hline & & 125 & $6.21^{\mathrm{b}}(4.17-9.86)$ & $1.76^{\mathrm{b}}(1.14-2.76)$ & $3.61^{\mathrm{b}}(3.30-3.79)$ & $1.26^{\mathrm{b}}(0.94-1.84)$ \\
\hline & & 200 & $7.40^{\mathrm{b}}(3.12-9.62)$ & $2.06^{\mathrm{b}}(1.00-2.77)$ & $3.58^{\mathrm{ab}}(3.11-3.92)$ & $1.41^{\mathrm{b}}(0.78-1.79)$ \\
\hline & & 350 & $6.10^{\mathrm{ab}}(2.59-9.67)$ & $1.67^{\mathrm{ab}}(0.66-2.72)$ & $3.54^{\mathrm{b}}(3.26-3.91)$ & $1.27^{\mathrm{ab}}(0.59-1.83)$ \\
\hline & & 500 & $6.78^{\mathrm{b}}(2.64-10.49)$ & $1.91^{\mathrm{b}}(0.72-2.99)$ & $3.57^{\mathrm{b}}(3.32-3.77)$ & $1.36^{\mathrm{b}}(0.66-1.94)$ \\
\hline & & Kruskal-Wallis & $\chi^{2}(6)=19.781$ & $\chi^{2}(6)=17.451$ & $\chi^{2}(6)=26.863$ & $\chi^{2}(6)=18.826$ \\
\hline & & Total $\mathrm{n}=130$ & $\mathrm{p}=0.003^{*}$ & $\mathrm{p}=0.008^{*}$ & $\mathrm{p}<0.001^{*}$ & $\mathrm{p}=0.004^{*}$ \\
\hline \multirow[t]{9}{*}{ Cyhalothrin } & Water & 0 & $3.80(0.88-10.20)$ & $1.16(0.33-2.89)$ & $3.36(2.68-3.75)$ & $0.89(0.40-1.95)$ \\
\hline & DMSO & 0 & $4.55(1.63-12.08)$ & $1.36(0.52-3.36)$ & $3.38(2.83-4.34)$ & $1.00(0.53-2.15)$ \\
\hline & & 50 & $4.14(1.61-6.26)$ & $1.26(0.49-1.81)$ & $3.40(3.18-3.78)$ & $0.97(0.44-1.28)$ \\
\hline & & 125 & $4.77(1.84-7.85)$ & $1.42(0.57-2.33)$ & $3.37(3.19-3.60)$ & $0.99(0.45-1.57)$ \\
\hline & & 200 & $4.30(3.24-10.86)$ & $1.26(1.10-3.01)$ & $3.23(2.83-3.61)$ & $0.94(0.78-2.01)$ \\
\hline & & 350 & 4.57 (2.61-8.79) & $1.29(0.77-2.58)$ & $3.38(3.27-3.59)$ & $1.00(0.58-1.66)$ \\
\hline & & 500 & $4.42(2.91-8.68)$ & $1.36(0.89-2.48)$ & $3.44(3.20-3.76)$ & $0.96(0.67-1.67)$ \\
\hline & & Kruskal-Wallis & $\chi^{2}(6)=7.547$ & $\chi^{2}(6)=8.197$ & $\chi^{2}(6)=2.986$ & $\chi^{2}(6)=6.544$ \\
\hline & & Total $\mathrm{n}=130$ & $\mathrm{p}=0.274$ & $\mathrm{p}=0.224$ & $\mathrm{p}=0.811$ & $\mathrm{p}=0.365$ \\
\hline \multirow[t]{9}{*}{ 3-PBA } & Water & 0 & $3.80(0.88-10.20)$ & $1.16(0.33-2.89)$ & $3.36(2.68-3.75)$ & $0.89(0.40-1.95)$ \\
\hline & DMSO & 0 & $4.55(1.63-12.08)$ & $1.36(0.52-3.36)$ & $3.38(2.83-4.34)$ & $1.00(0.53-2.15)$ \\
\hline & & 50 & $3.79(1.74-6.92)$ & $1.14(0.37-2.02)$ & $3.33(3.20-4.76)$ & $0.91(0.53-1.44)$ \\
\hline & & 125 & $3.60(2.02-6.45)$ & $1.10(0.58-1.88)$ & $3.39(2.98-3.72)$ & $0.79(0.62-1.24)$ \\
\hline & & 200 & $3.96(2.75-6.05)$ & $1.16(0.78-1.77)$ & $3.41(3.28-3.62)$ & $0.88(0.54-1.23)$ \\
\hline & & 350 & $4.29(1.18-6.05)$ & $1.24(0.33-1.86)$ & $3.35(3.00-3.61)$ & $0.92(0.30-1.18)$ \\
\hline & & 500 & $5.96(1.96-8.87)$ & $1.78(0.55-2.53)$ & $3.43(3.24-3.61)$ & $1.21(0.57-1.72)$ \\
\hline & & Kruskal-Wallis & $\chi^{2}(6)=9.109$ & $\chi^{2}(6)=8.978$ & $\chi^{2}(6)=2.759$ & $\chi^{2}(6)=9.556$ \\
\hline & & Total $\mathrm{n}=130$ & $\mathrm{p}=0.168$ & $\mathrm{p}=0.175$ & $\mathrm{p}=0.838$ & $\mathrm{p}=0.145$ \\
\hline
\end{tabular}

* Statistically significant differences for a p value $<0.05$. The same letters (a-i) in a row that the given medians are not statistically different ( $>0.05$ )

maintained at a similar level (Kitajima and Hogan, 2003). Consequently, the ratio of PSII to LHCII (and the $\mathrm{Ch}_{a / b}$ ratio) should increase with decreasing $\mathrm{N}$ availability.

For cyhalothrin and 3-PBA, the imposed stress had no effect on the pigments leaves of $C$. sativus, as no statistically significant differences were observed to all the assessed investigated pigments content.

Although the water and DSMO controls did not show significant differences the results obtained in terms of germination/growth suggest a synergistic effect of DSMO together with the pyrethroids applied. It seems likely that the organic solvent may also have an effect in chlorophylls in addition to the other tested parameters. The need for the utilization of a solvent in order to solubilize the tested compounds points to the importance of other compounds used in the formulation of the final product, other than the pesticide itself, which can have indirect effects on the Environment.

\section{Conclusions}

Cypermethrin, deltamethrin, and cyhalothrin are some of the most used synthetic pyrethroids in agriculture applications, namely for plants pest control. Due to their capacity to bind to soil particles and passed through plants, it's of significant importance to assess their environmental toxicity. Their metabolites, such as 3-PBA, can also cause impact on the environment. Phytotoxicity can be assessed using such parameters as germination, seedling development (root, leaf, and shoot) and chlorophyll/carotenoid contents. A direct effect of 3-PBA on germination was observed while the pyrethroids tested did not show any influence on this parameter. For the tested pyrethroids cypermethrin was the one with most impact on seedling development, namely on leaf and shoot elongation. Root elongation was more affected by deltamethrin. The impacts of the four compounds were also evaluated through the determination of chlorophyll and carotenoids contents after 7 days of exposure. Studies with deltamethrin were the ones that presented higher values for these two parameters with statistically significant differences for chlorophyll $a$, b, their ratio and for carotenoids $\left(C_{x}+c\right)$.

The results highlight the effect that pyrethroids have on the early growth of plants. The assessed parameters, seedling germination, and development as well as chlorophyll and carotenoids contents, contributed to the knowledge of the phytotoxicity of these three different pyrethroids and their metabolite. A higher emphasis is necessary for research in commonly applied agrochemicals that affect the biology of non-target organisms, as was shown for the tested compounds.

\section{Acknowledgements}

I. Bragança is grateful to FCT for the doctoral research grant financed by fellowship (SFRH/BD/52504/2014). This work received financial support from the European Union (FEDER (POCI/01/0145/FEDER/007265) funds through COMPETE) and National Funds (FCT, Fundação para a Ciência e Tecnologia) through projects UID/QUI/50006/2013. The authors are greatly indebted to all financing sources.

\section{References}

Aksoy, O., Deveci, A., 2012. The investigation of the cytotoxic effects of some pesticides on soybean (Glycine max L.). Cytologia 77, 475-483. 
Albaseer, S.S., Rao, R.N., Swamy, Y.V., Mukkanti, K., 2011. Analytical artifacts, sample handling and preservation methods of environmental samples of synthetic pyrethroids. TrAC Trends Anal. Chem. 30, 1771-1780.

Antwi, F.B., Reddy, G.V.P., 2015. Toxicological effects of pyrethroids on non-target aquatic insects. Environ. Toxicol. Pharmacol. 40, 915-923.

Aznar, R., Moreno-Ramon, H., Albero, B., Sanchez-Brunete, C., Tadeo, J.L., 2017. Spatiotemporal distribution of pyrethroids in soil in Mediterranean paddy fields. J. Soils Sediments 17, 1503-1513.

Braganca, I., Placido, A., Paiga, P., Domingues, V.F., Delerue-Matos, C., 2012. QuEChERS: a new sample preparation approach for the determination of ibuprofen and its metabolites in soils. Sci. Total Environ. 433, 281-289.

Bronshtein, A., Chuang, J.C., Van Emon, J.M., Altstein, M., 2012. Development of multianalyte enzyme-linked immunosorbent assay for permethrin and aroclors and its implementation for analysis of soil/sediment and house dust extracts. J. Agric. Food Chem. 60, 4235-4242.

Chen, S., Hu, M., Liu, J., Zhong, G., Yang, L., Rizwan-ul-Haq, M., et al., 2011. Biodegradation of beta-cypermethrin and 3-phenoxybenzoic acid by a novel Ochrobactrum lupini DGS-01. J. Hazard. Mater. 187, 433-440.

Cycoń, M., Piotrowska-Seget, Z., 2016. Pyrethroid-degrading microorganisms and their potential for the bioremediation of contaminated soils: a review. Front. Microbiol. $7,1463$.

Dubey, K.K., Fulekar, M.H., 2011. Effect of pesticides on the seed germination of Cenchrus setigerus and Pennisetum pedicellatum as monocropping and co-cropping system: implications for rhizospheric bioremediation. Roum. Biotechnol. Lett. 16, 5909-5918.

Edge, R., Truscott, T.G., 1999. Carotenoid radicals and the interaction of carotenoids with active oxygen species. In: Frank, H.A., Young, A.J., Britton, G., Cogdell, R.J. (Eds.), The Photochemistry of Carotenoids. Springer Netherlands, Dordrecht, pp. 223-234.

Giri, S., Shrivastava, D., Deshmukh, K., Dubey, P., 2013. Effect of air pollution on chlorophyll content of leaves current agriculture research. Journal 1, 93-98.

Gomes, M.P., FVDS, Cruz, Bicalho, E.M., Borges, F.V., Fonseca, M.B., Juneau, P., et al., 2017. Effects of glyphosate acid and the glyphosate-commercial formulation (roundup) on Dimorphandra wilsonii seed germination: interference of seed respiratory metabolism. Environ. Pollut. 220 (Part A), 452-459.

Gonzalez-Naranjo, V., Boltes, K., de Bustamante, I., Palacios-Diaz, P., 2015. Environmental risk of combined emerging pollutants in terrestrial environments: chlorophyll $a$ fluorescence analysis. Environ. Sci. Pollut. Res. 22, 6920-6931.

Gosselin, R.E., Smith, R.P., Hodge, H.C., Braddock, J.E., 1984. Clinical Toxicology of Commercial Products. Williams \& Wilkins, Baltimore.

Gu, X.Z., Zhang, G.Y., Chen, L., Dai, R.L., Yu, Y.C., 2008. Persistence and dissipation of synthetic pyrethroid pesticides in red soils from the Yangtze River Delta area. Environ. Geochem. Health 30, 67-77.

Hanley, M.E., Whiting, M.D., 2005. Insecticides and arable weeds: effects on germination and seedling growth. Ecotoxicology 14, 483-490.

Haya, K., 1989. Toxicity of pyrethroid insecticides to fish. Environ. Toxicol. Chem. 8 381-391.

Hewitt, P.D., Rennie, W.J., 1986. Biological tests for seeds. In: Jeffs, K.A. (Ed.), Seed Treatment. British Crop Protection Council, Croydon, UK, pp. 51-82.

Hikosaka, K., Terashima, I., 1995. A model of the acclimation of photosynthesis in the leaves of C3 plants to sun and shade with respect to nitrogen use. Plant Cell Environ. $18,605-618$.

Ibanez, H., Ballester, A., Munoz, R., Quiles, M.J., 2010. Chlororespiration and tolerance to drought, heat and high illumination. J. Plant Physiol. 167, 732-738.

Johnson, M.P., Portland Press Ltd, 2016. Photosynthesis. Understanding Biochemistry 2. 60. Portland Press Ltd, London, pp. 255-273.

Kachout, S.S., Ben Mansoura, A., Ennajah, A., Leclerc, J.C., Ouerghi, Z., Bouraoui, N.K., 2015 Effects of metal toxicity on growth and pigment contents of annual halophyte $(A$. hortensis and A. rosea). Int. J. Environ. Res. 9, 613-620.

Kapanen, A., Itävaara, M., 2001. Ecotoxicity tests for compost applications. Ecotoxicol. Environ. Saf. 49, 1-16.

Kitajima, K., Hogan, K.P., 2003. Increases of chlorophyll $a / b$ ratios during acclimation of tropical woody seedlings to nitrogen limitation and high light. Plant Cell Environ. 26, 857-865.

Kumar, R.S.S., Shiny, P.J., Anjali, C.H., Jerobin, J., Goshen, K.M., Magdassi, S., et al., 2013. Distinctive effects of nano-sized permethrin in the environment. Environ. Sci. Pollut. Res. 20, 2593-2602.

Liu, T.F., Wang, T., Sun, C., Wang, Y.M., 2009. Single and joint toxicity of cypermethrin and copper on Chinese cabbage (Pakchoi) seeds. J. Hazard. Mater. 163, 344-348.

Luo, Y.Z., Zhang, M.H., 2011. Environmental modeling and exposure assessment of sediment-associated pyrethroids in an agricultural watershed. PLoS One 6.
Margesin, R., Schinner, F., 2005. Manual for Soil Analysis: Monitoring and Assessing Soil Bioremediation. Springer, p. 366

Moore, M.T., Locke, M.A., 2012. Phytotoxicity of atrazine, S-metolachlor, and permethrin to Typha latifolia (Linneaus) germination and seedling growth. Bull. Environ. Contam. Toxicol. 89, 292-295.

OECD, 2006. Terrestrial Plant Test: Seedling Emergence and Seedling Growth Test. OECD Guideline for Testing of Chemicals. Organization for Economic Cooperation and Development, Paris, France.

Oudou, H.C., Hansen, H.C., 2002. Sorption of lambda-cyhalothrin, cypermethrin, deltamethrin and fenvalerate to quartz, corundum, kaolinite and montmorillonite. Chemosphere 49, 1285-1294.

Palmquist, K., Salatas, J., Fairbrother, A., 2012. Chapter 11 - pyrethroid insecticides: use, environmental fate, and ecotoxicology. In: Perveen, D.F. (Ed.), Insecticides. Advances in Integrated Pest Management.

Porra, R.J., 2002. The chequered history of the development and use of simultaneous equations for the accurate determination of chlorophylls $a$ and $b$. Photosynth. Res. 73, 149-156

Raghavendra, K., Barik, T.K., Reddy, B.P.N., Sharma, P., Dash, A.P., 2011. Malaria vector control: from past to future. Parasitol. Res. 108, 757-779.

Ranson, H., N'Guessan, R., Lines, J., Moiroux, N., Nkuni, Z., Corbel, V., 2011. Pyrethroid resistance in African anopheline mosquitoes: what are the implications for malaria control? Trends Parasitol. 27, 91-98.

Rede, D., Santos, L., Ramos, S., Oliva-Teles, F., Antao, C., Sousa, S.R., et al., 2016. Ecotoxicological impact of two soil remediation treatments in Lactuca sativa seeds. Chemosphere 159, 193-198.

Strzalka, K., Kostecka-Gugala, A., Latowski, D., 2003. Carotenoids and environmental stress in plants: significance of carotenoid-mediated modulation of membrane physical properties. Russ. J. Plant Physiol. 50, 168-172.

Sumanta, N. Haque, C.I., Nishika, J., Suprakash, R., 2014. Spectrophotometric analysis of chlorophylls and carotenoids from commonly grown Fern species by using various extracting solvents. Res. J. Chem. Sci. 4, 63-69.

Tyler, C.R., Beresford, N., van der Woning, M., Sumpter, J.P., Tchorpe, K., 2000. Metabolism and environmental degradation of pyrethroid insecticides produce compounds with endocrine activities. Environ. Toxicol. Chem. 19, 801-809.

USEPA, 1996. Protocols for short term toxicity screening of hazardous waste sites. In: Greene, J.C., Bartels, C.L., Warren-Hicks, W.J., Parkhurst, B.R., Linder, G.L., Peterson, S.A., et al. (Eds.), EPA 600/3-88/029, Chicago, USA.

Wagner, V., Nelson, C.R., 2014. Herbicides can negatively affect seed performance in native plants. Restor. Ecol. 22, 288-291.

Wang, W., Williams, J.M., 1988. Screening and biomonitoring of industrial effluents using phytotoxicity tests. Environ. Toxicol. Chem. 7, 645-652.

Wellburn, A.R., 1994. The spectral determination of chlorophylls a and b, as well as total carotenoids, using various solvents with spectrophotometers of different resolution. J. Plant Physiol. 144, 307-313.

Weston, D.P., Holmes, R.W., You, J., Lydy, M.J., 2005. Aquatic toxicity due to residential use of pyrethroid insecticides. Environ. Sci. Technol. 39, 9778-9784.

Weston, D.P., Ding, Y., Zhang, M., Lydy, M.J., 2013. Identifying the cause of sediment toxicity in agricultural sediments: the role of pyrethroids and nine seldom-measured hydrophobic pesticides. Chemosphere 90, 958-964.

Wright, S.W., Jeffrey, S.W., FRC, Mantoura, 1997. Evaluation of Methods and Solvents for Pigment Analysis. Phytoplankton Pigments in Oceanography: Guidelines to Modern Methods. UNESCO, Paris, pp. 261-282.

Xu, Z., Shen, X., Zhang, X.-C., Liu, W., Yang, F., 2015. Microbial degradation of alphacypermethrin in soil by compound-specific stable isotope analysis. J. Hazard. Mater. $295,37-42$

Yu, P., Li, S.J., Zhang, Z.F., Wen, X.L., Quan, W., Tian, Q.L., et al., 2017. Progesterone-mediated angiogenic activity of endothelial progenitor cell and angiogenesis in traumatic brain injury rats were antagonized by progesterone receptor antagonist. Cell Prolif. 50.

Zarco-Tejada, P.J., Berni, J.A.J., Suarez, L., Sepulcre-Canto, G., Morales, F., Miller, J.R., 2009. Imaging chlorophyll fluorescence with an airborne narrow-band multispectral camera for vegetation stress detection. Remote Sens. Environ. 113, 1262-1275.

Zhang, W., Jiang, F., Ou, J., 2011. Global Pesticide Consumption and Pollution: With China as a Focus. Proceedings of the International Academy of Ecology and Environmental Sciences. 1 pp. $125-144$. 